\title{
Profound hypotension in a tetraplegic patient following angiotensin-converting enzyme inhibitor lisinopril. Case report
}

\author{
J K Schmitt MD, K S Koch PA-C, M Midha MD \\ Departments of Internal Medicine and Spinal Cord Injury Service, Hunter Holmes \\ McGuire Veterans Administration Medical Center, Richmond, Virginia 23249, USA
}

\begin{abstract}
We present the case of a 60 year old C6 complete tetraplegic patient who developed profound hypotension following initiation of the angiotensin-converting enzyme inhibitor lisinopril to control blood pressure. Other causes of hypotension, such as myocardial infarction and sepsis were ruled out. Inhibition of the renin-angiotensin-aldosterone system was the probable cause of hypotension. This case demonstrates the critical importance of the reninangiotensin-aldosterone axis in the maintenance of blood pressure in tetraplegic patients, who may lack input from the brain to sympathetic neurons, and therefore have increased reliance on the renin-angiotensin-aldosterone axis for the maintenance of blood pressure. Angiotensin-converting enzyme inhibitors should be avoided in tetraplegic patients, unless other treatment modalities are ineffective.
\end{abstract}

Keywords: tetraplegia; angiotensin-converting enzyme inhibitors.

\section{Introduction}

Arterial blood pressure is determined by the product of cardiac output and peripheral vascular resistance $(\mathrm{BP}=\mathrm{CO} \times \mathrm{PVR})$.

A major determinant of cardiac output is intravascular volume, which is in part controlled by aldosterone, which increases renal sodium reabsorption. Major determinants of the peripheral vascular resistance are the sympathetic nervous system, and angiotensin II, a potent vasoconstrictor. ${ }^{1}$

As a result of loss of neurological connections between the brain and sympathetic neurons, sympathetic tone in tetraplegics is decreased. ${ }^{1.2 .3}$ Tetraplegics therefore tend to be hypotensive, especially when upright. An exception to this tendency is in autonomic dysreflexia, when stimuli, such as bladder distension and fecal impaction trigger spinal sympathetic reflexes that are normally inhibited by higher neuronal connections. ${ }^{4}$

The renin-angiotensin-aldosterone axis

This paper was presented in part at the 20th Annual meeting of The American Spinal Injury Association, Philadelphia, PA, April 25-27, 1994. does not require an intact sympathetic nervous system for activity. ${ }^{1.5 .6}$ The major stimulus to renin production is decreased renal perfusion pressure. Tetraplegics are therefore felt to have increased dependence on the renin-angiotensin-aldosterone axis to maintain blood pressure, especially in the upright position. In support of this hypothesis is the evidence that supine and upright renin and aldosterone are increased in spinal cord injury patients in comparison to ambulatory controls. ${ }^{1.5 .6}$ Other possible adaptations of tetraplegics that might increase blood pressure include increased sensitivity to circulating catecholamines, ${ }^{7}$ decreased renal response to atrial natriuretic factor, ${ }^{8}$ and increased serum vasopressin levels. $^{9}$

Angiotensin II is a potent vasoconstrictor which also stimulates aldosterone production by the adrenal gland. ${ }^{10}$ Aldosterone causes renal sodium and water reabsorption, thereby increasing intravascular volume and cardiac output.

Over the past decade there has been increased use of angiotensin-converting enzyme inhibitors for the treatment of hypertension and congestive heart failure. These 
drugs competitively inhibit the converting enzyme by attaching to its binding site on angiotensin-I. ${ }^{10}$ Angiotensin-II mediated vasoconstriction is thereby decreased, and blood pressure falls. Synthesis of aldosterone is also inhibited, resulting in natriuresis. Because angiotensin-converting enzyme also inactivates bradykinin, increased bradykinin levels may also contribute to ACE inhibitors' antihypertensive action. ${ }^{11}$

The potentially critical importance of the renin-angiotensin-aldosterone axis in the maintenance of blood pressure in tetraplegic patients has led to speculation that the use of angiotensin-converting enzyme inhibitors in these patients might produce severe hypotension. Until now there have been few reports of this phenomenon.

Treatment of tetraplegics with captopril, a short acting ACE inhibitor, has been found to decrease the blood pressure during head up tilt. ${ }^{12}$

Lisinopril is a long acting angiotensinconverting enzyme inhibitor which is excreted unchanged in the urine. ${ }^{13}$ We report a case of profound hypotension in a tetraplegic patient secondary to lisinopril.

\section{Case report}

A 61 year old incomplete C6 tetraplegic patient was admitted to the Spinal Cord Injury Service of Hunter Holmes McGuire Veterans Administration Medical Center on 12 May 1993 for the treatment of a pressure ulcer of the left lateral malleolus. Past medical history included tetraplegia secondary to an automobile accident in 1952, chronic obstructive pulmonary disease, congestive heart failure, and malignant melanoma. He had smoked one pack of cigarettes per day for 50 years. Medications included sustained release theophylline $200 \mathrm{mg}$ every $12 \mathrm{~h}$, prednisone $20 \mathrm{mg}$ per day, and ranitidine $150 \mathrm{mg}$ by mouth every $12 \mathrm{~h}$.

Physical examination revealed an obese man lying with head up at a 30 degree angle in bed in mild respiratory distress. Blood pressure was $120 / 80 \mathrm{mmHg}$, pulse $80 . \mathrm{T} 97 . \mathrm{OF}$. The right eye had been enucleated secondary to a melanoma. Chest auscultation revealed scattered bilateral wheezes and basilar rales. Cardiovascular examination showed no murmurs or gallops. The abdomen was obese. Neurological examination was consistent with incomplete C6 tetraplegia. There was a grade II pressure ulcer on the left lateral malleolus. Because of the history of congestive heart failure, fluid restriction to $2000 \mathrm{cc}$ per day was begun on May 13, 1993. Urine output declined from $1600 \mathrm{cc}$ per day to about $1200 \mathrm{cc} /$ day and by 4 June weight had decreased from $95 \mathrm{~kg}$ to $90 \mathrm{~kg}$.

Beginning on 4 June an elevated blood pressure was noted (Fig 1). The pulse rate at that time was $90 / \mathrm{min}$. No cause of the hypertension was found. On 8 June lisinopril $5 \mathrm{mg}$ per day was begun. The blood pressure gradually began to fall. Cardiovascular examination was unchanged; however wheezes and rales diminished in intensity. On June 11, the blood pressure was found to be $80 / 50$ with a pulse rate of $117 / \mathrm{min}$ (Fig 1). Subsequent blood pressure recordings were palpable only at $50-60 \mathrm{mmHg}$.

The patient was placed in a head down position. However this worsened his pulmonary function. Saline was given intravenously without improvement in blood pressure. The patient was transferred to the intensive care unit and a dopamine drip $5 \mu \mathrm{g} \mathrm{kg} / \mathrm{min}$ was begun. This failed to elevate the blood pressure, and the dopamine was increased to $10 \mu \mathrm{g} / \mathrm{kg} \min$. The blood pressure increased to $110-120 / 80 \mathrm{mmHg}$ with a pulse rate of $114 / \mathrm{min}$ (Fig 1). Whilst on the dopamine drip the urine output increased from $20 \mathrm{cc} / \mathrm{h}$ to $50 \mathrm{cc} / \mathrm{h}$.

Laboratory values in the intensive care unit showed a serum sodium $124 \mathrm{meq} / \mathrm{l}$ (which was decreased from the admission value), potassium $4.0 \mathrm{meq} / \mathrm{l}$, chloride $88 \mathrm{meq} / \mathrm{l}$, HCO3 $21 \mathrm{meq} / 1$, BUN $53 \mathrm{mg} / \mathrm{dl}$, creatinine $0.9 \mathrm{mg} / \mathrm{dl}$, glucose $85 \mathrm{mg} / \mathrm{dl}$. The cardiac enzymes were normal. The electrocardiogram was unchanged from admission ECG. Arterial blood gases on 31 oxygen per min showed $\mathrm{PO}_{2} 118 \mathrm{mmHg}, \mathrm{PCO}_{2}$ $37 \mathrm{mmHg}, \mathrm{PH} 7.30, \mathrm{HCO} 320 \mathrm{meq} / \mathrm{l}$. Chest $\mathrm{x}$-ray revealed slight cardiomegaly, with no acute changes. Blood cultures were negative. The lack of decrease in $\mathrm{PO}_{2}$ was felt to be strong evidence against pulmonary embolism. After 2 days the dopamine was discontinued, the blood pressure remained $120 / 80 \mathrm{mmHg}$ and the patient was transferred out of the intensive care unit.

\section{Discussion}

The temporal sequence of events suggests that the profound hypotension seen in this patient was due to lisinopril. Other possible causes of shock, including myocardial infarction, pulmonary embolism and sepsis, were ruled out. After several days, dopamine was no longer required to maintain the 


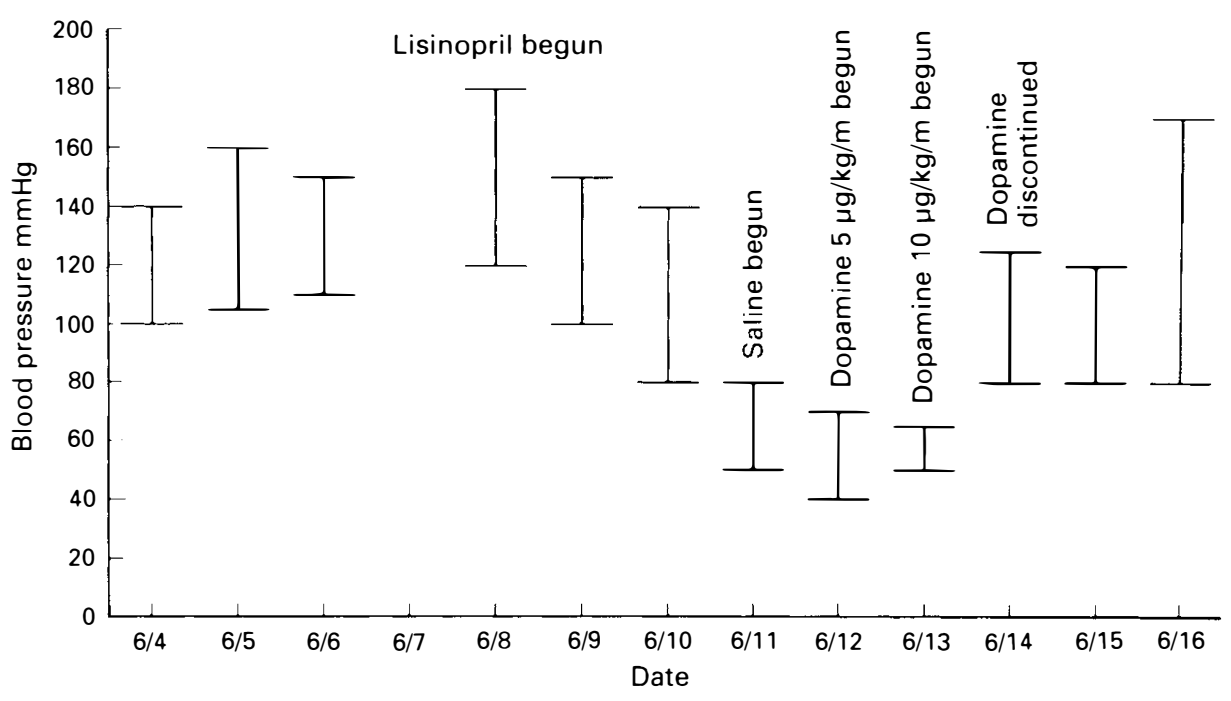

Figure 1 Effect of lisinopril on the blood pressure of a C6 tetraplegic patient. (Cross bars indicate systolic and diastolic blood pressures).

blood pressure. This time period is consistent with the half life of lisinopril of $7 \mathrm{~h} .{ }^{13}$ Although lisinopril is cleared by renal mechanisms, its serum half life does not increase until creatinine clearance goes below $30 \mathrm{cc} / \mathrm{min}$, which did not occur in this case. There were no significant interactions between lisinopril and the patient's other medications.

The patient was fluid restricted for several days. This maneuver is used in ambulatory hypertensive patients to increase their sensitivity to ACE inhibitors, and in this case is likely to have further increased the dependence on angiotensin II to sustain blood pressure. The hypotension was most likely due to a fall in angiotensin II. Decreased aldosterone production probably also contributed to the fall in blood pressure by decreasing renal sodium retention. In support of this hypothesis is the finding of hyponatremia in the intensive care unit.
The hypertensive episode was probably secondary to autonomic dysreflexia. However, no obvious causes of autonomic dysreflexia were found. Autonomic dysreflexia is treated with removal of the stimulus such as bladder distension or by medications such as alpha-adrenergic blockers. ${ }^{14}$

Angiotensin-converting enzyme inhibitors are effective antihypertensives, and by reducing afterload also benefit patients with congestive heart failure. However, in tetraplegic people there is the potential risk of life-threatening hypotension, as is illustrated by our patient. The dose of lisinopril (5 mg) was small and unlikely to cause hypotension in ambulatory patients, but in this case it almost resulted in fatal hypotension. ACE inhibitors should be avoided in these patients. Alternate agents such as calcium channel blockers and peripheral alpha-adrenergic blockers ${ }^{14}$ may be safely used in spinal cord injury patients.

\section{References}

1 Mathias CJ, Frankel HL, Vinkin PJ, Bruyn G, Klawans HL (1992) Cardiovascular system in tetraplegia and paraplegia. In Handbook of Clinical Neurology. Elsevier, New York: 435-456.

2 Mathias CJ, Christensen NJ, Corbett JL, Frankel HL, Spalding JM (1976) Plasma catecholamines during paroxysmal neurogenic hypertension in quadriplegic man. Circ Res 39: 204-208.

3 Stjernberg L, Blumberg H. Wallen B (1986) Sympathetic activity in man after spinal cord injury. Brain 109: 695-715.

4 Guttmann L, Whitteridge D (1947) Effects of bladder distension on autonomic mechanisms after spinal cord injuries. Brain 70: 361-404. 
5 Mathias CJ, Christensen NJ, Corbett JL et al (1975) Plasma catecholamines, plasma renin activity and plasma aldosterone in tetraplegic man, horizontal and tilted. Clin Sci Mol Med 49: 291-299.

6 Mathias CJ, Christensen NJ, Frankel HL, Peart WS. Renin release during head-up tilt occurs independently of sympathetic nervous system activity in tetraplegic man. Clin Sci 59: 251-256.

7 Mathias CJ, Frankel HL. Christensen NJ, Spalding JM (1976) Enhanced pressor response to noradrenaline in patients with cervical spinal cord transection. Brain 99: 757-770.

8 Sica DA, Midha M, Aronoff G, Bergen G (1994) Atrial natriuretic factor in spinal cord injury. Arch Phys Med Rehabil 74: 969-972.

9 DiPette D, Gavras I, North W et al (1984) Vasopressin response to hyperosmotic stimulus: blood pressure effect in normal subjects and patients with impaired sympathetic nervous system. Clin Exp Hypertens Part A, Theory and Practice 6: 851-861.

10 Balfour JA, Goa KL (1991) Benazepril. A review of its pharmacodynamic and pharmacokinetic properties and therapeutic efficiency in hypertension and congestive heart failure. Drugs 42: 511-539.

11 Cachofeiro V, Sakakibara T, Nasjletti A (1992) Kinins, nitric oxide and the hypotensive effect of captopril and ramiprilat in hypertension. Hypertension 19: 138-154.

12 Alam M, Unwin R, Frankel H et al (1992) Cardiovascular and hormonal effects of captopril in tetraplegia. Clin Auton Res 2: 59.

13 Physicians Gen Rx Inc. Patricia Denniston, Smithtown, New York.

14 Krum H, Louis WJ, Brown DJ, Howes LG (1992) A study of the alpha-1 adrenoreceptor blocker prazosin in the prophylactic management of autonomic dysreflexia in high spinal cord injury patients. Clin Auton Res 2: $83-88$. 